\title{
Imaging in nasopharyngeal carcinoma: the value of 18-Florine Fluorodeoxyglucose PET/CT in comparison to conventional imaging modalities $\mathrm{CT}$ and MRI
}

\section{Abdul Jalil Nordin ${ }^{1}$, Simona Secondino ${ }^{2}$, Noraini Abdul Rahim ${ }^{3}$, Paolo Pedrazzoli ${ }^{2}$, Salvatore Siena ${ }^{2}$, Claudio Rossetti ${ }^{4}$, Tahir Aris ${ }^{5}$}

\author{
${ }^{1}$ Nuclear Imaging Unit, Faculty Medicine and Health Science, University Putra Malaysia \\ ${ }^{2}$ Oncologia Medica Falck, Ospedale Niguarda Ca' Granda, Milan, Italy ${ }^{3}$ Radiology Department, \\ Hospital Serdang, Serdang, Malaysia ${ }^{4}$ Department of Nuclear Medicine, Ospedale Niguardia \\ Ca' Granda, Milan, Italy ${ }^{5}$ Institute for Health Systems Research, Ministry Of Health Malaysia
}

Background. The aim of the study was to evaluate the clinical usefulness of 18F Fluorodeoxyglucose (FDG) positron emission tomography / computed tomography (PET/CT) in the management of nasopharyngeal carcinoma (NPC) in comparison to conventional imaging modalities.

Methods. This retrospective study was done at Ospedale Niguarda, Milan, Italy. Data were acquired from 24 NPC patients between May 2003 and December 2006. They had FDG PET/CT and CT or MRI during the initial diagnosis and at follow-up. Each finding was tabulated and compared with tissue biopsy at diagnosis and clinical status during the follow up after the therapy. A statistical calculation was done to derive the value of each modality.

Results. The sensitivity and accuracy of PET/CT and CT/MRI were equally high at diagnosis. At the follow up, a negative PET/CT finding suggested a complete remission with sensitivity and negative predictive value of $100 \%$.

Conclusions. 18F FDG PET/CT is a potential modality to be utilized in following up NPC patients for evaluating a response to therapy.

Key words: positron emission tomography; computed tomography; magnetic resonance imaging; nasopharyngeal carcinoma; follow-up

Received 11 May 2009

Accepted 28 May 2009

Correspondence to: Abdul Jalil Nordin, MD, Nuclear Imaging Unit, Faculty Medicine and Health Science, University Putra Malaysia, 43400 Serdang, Selangor, Malaysia; E-mail: drimaging@yahoo.com

\section{Introduction}

Nasopharyngeal carcinoma (NPC) is common among the Chinese populations especially in the south China and South East Asia region with incidence of 20 to 50 per 100000 individuals. ${ }^{1,2}$ Despite being uncommon among other ethnic groups including the Europeans, a higher incidence 
has been reported among the south Indian community as well as in the North African community. ${ }^{3}$

Ebstein Barr Viral (EBV) infection is thought to play an important role in initiating the development of this tumour. Multiple literature review revealed the coexistence between EBV infection and NPC. ${ }^{4-10}$ There is a huge clinical value of the data about EBV infection, because no factor in a wide spectrum of biochemical and histological candidate-markers has yet been identified to predict reliably the natural course of the disease or its response to the therapy to be used in the routine clinical practice, ${ }^{11}$ but, Kenneth et al. suggested that EBV status could be a reliable predictor for the overall survival of NPC patients. $^{12}$

Most NPC patients commonly manifest themselves with painless enlarged lymph nodes in the neck which are often bilateral. When these are in association with positive EBV's DNA, they are highly suspicious for nodal disease from NPC primary. ${ }^{13}$ Other clinical features include nasal obstruction and epistaxis which may occur as a result of the local tumour infiltration. Patients may also suffer from hearing problems like hearing loss, tinnitus or recurrent otitis media. In advanced cases, the cranial nerve dysfunction may occur. A more generalized presentation like sore throat and headache are not uncommon. These clinical presentations are looked for at diagnosis and follow up.

Besides histological typing, the early detection and accurate staging at diagnosis and restaging at follow up are important prognostic determinants. Early and accurate staging at diagnosis will ensure proper treatment deliveries as the prevalence of head and neck metastases is as high as $40 \%$ at the time of the initial presentation. Accurate restaging after therapy is also important to determine the treatment response and to answer the question whether the patient requires a change in the pre planned treatment regime.

In the current practice, conventional imaging modalities like CT and MR are routinely employed to assist clinicians in staging NPC patients. A fused integrated morphological and functional imaging modality of positron emission tomography / computed tomography (PET/CT) is another possible useful new tool to be utilized in the assessment of NPC patients like in other oncological patients. ${ }^{14}$ This study was conducted in view to evaluate the role of fused PET/CT in the management of NPC patients.

This study was approved by the institutional review board of the hospital.

\section{Patients and methods}

\section{Patients}

Retrospective data from 33 patients between May 2003 to December 2006, from Nuclear Medicine Department, Ospedale Niguarda, Milan, Italy were reviewed. These are confirmed cases of nasopharyngeal carcinoma from histopathological tissue biopsy. The results were collected and tabulated.

Since this study was selective for comparison between PET/CT and conventional imaging tools, only paired PET/CT with CT or MRI imaging results were included. Patients with incomplete imaging data were excluded from this study. Finally, we selected imaging results from 24 patients for the analysis. There were 7 women and 17 men, age between 21-75 years included in the study. Patients were grouped into three categories.

Group A patients had a combination of examinations consisting of 18F-FDG PET/ CT, CT and or MRI examinations at diagnosis and after the treatment. These patients received radio or chemotherapy singly or in combination following the confirmation of the diagnosis of NPC. Post therapy imag- 


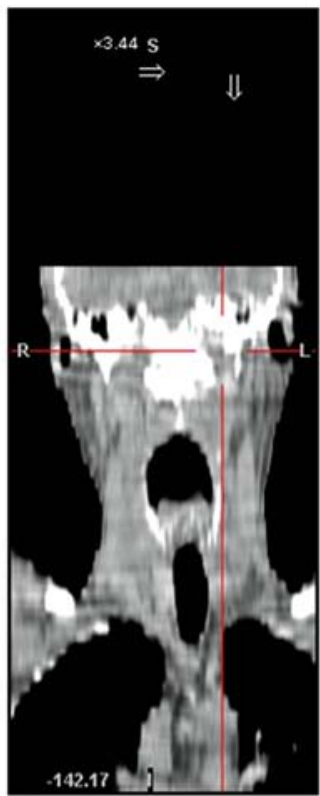

CT Coronals

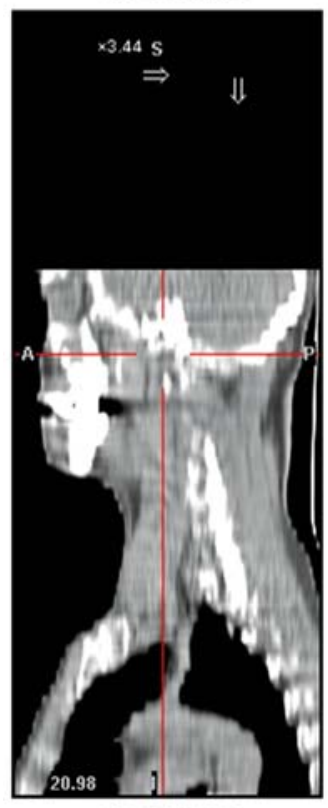

CT Sagittals

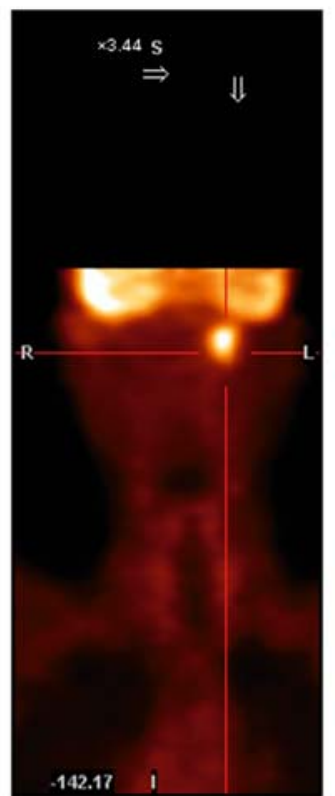

PET Coronals

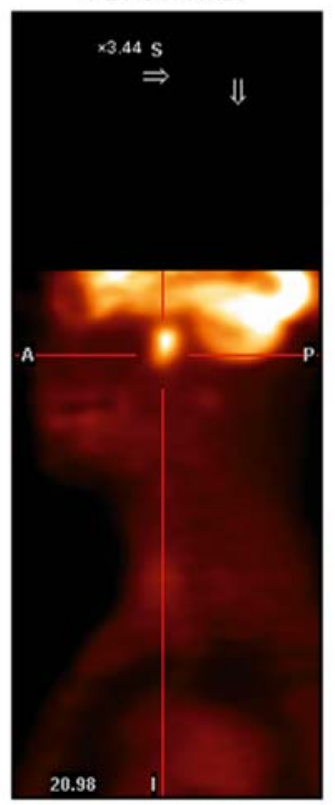

PET Sagittals

ing was conducted at 5 - 6 months upon the completion of the last treatment.

Group B patients consisting only newly diagnosed NPC patients and had a combination of examinations at the initial stag-

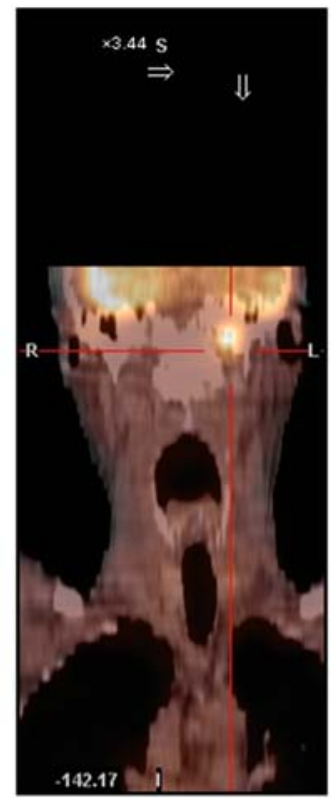

Fused Coronals

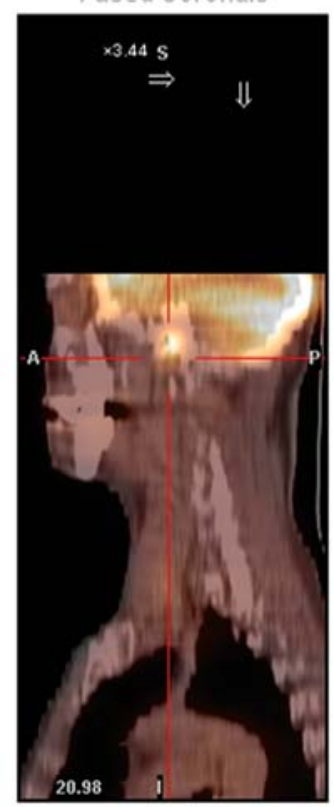

Fused Sagittals

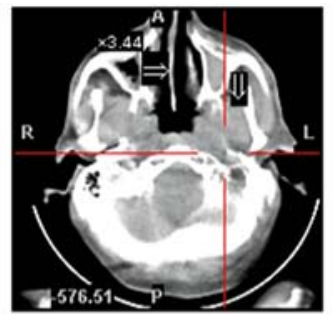

CT Transaxials

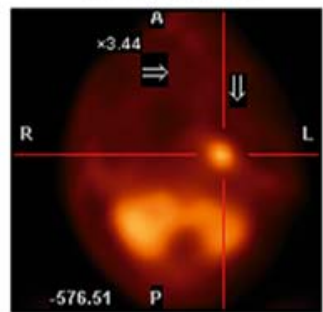

PET Transaxials

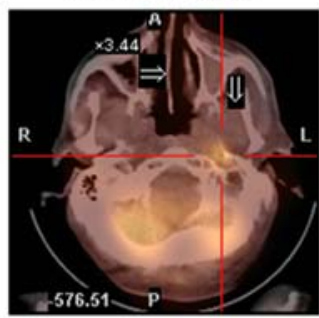

Fused Transaxials

Figure 1. A 61 year old man who presented with epistaxis at diagnosis of nasopharyngeal carcinoma. Multiplanar reconstructed images obtained during ${ }^{18}$ F-FDG PET/CT examination revealed mild distortion of the normal anatomy of the left nasopharyngeal region (red crossed cursor). 18F-FDG PET CT demonstrating avid activity with intense metabolic activity deeply seated in the left nasopharyngx.

ing process. These patients are still under follow up. They will be reassessed during their next follow up visit to the clinic. Thus, there is only one PET/CT study performed at diagnosis. 
Table 1. Clinical, histopathological and imaging results

\begin{tabular}{|c|c|c|c|c|c|c|c|}
\hline \multirow[b]{2}{*}{ Group A } & \multirow[b]{2}{*}{ Age/Sex } & \multicolumn{2}{|c|}{ At diagnosis } & \multirow[b]{2}{*}{ HPE } & \multicolumn{2}{|c|}{ Following treatment } & \multirow[b]{2}{*}{ Disease status } \\
\hline & & PET/CT & CT/MR & & PET/CT & $\mathrm{CT} / \mathrm{MR}$ & \\
\hline 1 & 64/M & pos & pos & und & neg & neg & remission \\
\hline 2 & $63 / \mathrm{M}$ & pos & pos & und & pos & pos & persistent \\
\hline 3 & $61 / \mathrm{M}$ & pos & pos & few diff & pos & pos & persistent \\
\hline 4 & $53 / \mathrm{M}$ & pos & pos & $\mathrm{N} / \mathrm{A}$ & pos & pos & persistent \\
\hline 5 & $48 / \mathrm{M}$ & pos & pos & few diff & pos & pos & persistent \\
\hline 6 & $39 / \mathrm{F}$ & pos & pos & und & pos & pos & remission \\
\hline 7 & $51 / \mathrm{M}$ & pos & pos & und & pos & pos & persistent \\
\hline 8 & $62 / \mathrm{M}$ & pos & pos & und & pos & pos & persistent \\
\hline 9 & $75 / \mathrm{M}$ & pos & pos & few diff & pos & pos & persistent \\
\hline 10 & $47 / \mathrm{F}$ & pos & pos & und & neg & neg & remission \\
\hline 11 & $37 / \mathrm{F}$ & pos & pos & und & pos & pos & persistent \\
\hline 12 & $63 / \mathrm{F}$ & pos & pos & und & pos & neg & persistent \\
\hline 13 & $21 / \mathrm{F}$ & pos & pos & und & pos & pos & persistent \\
\hline \multicolumn{8}{|l|}{ Group B } \\
\hline 14 & $61 / \mathrm{F}$ & pos & pos & und & $\mathrm{n} / \mathrm{a}$ & $\mathrm{n} / \mathrm{a}$ & $\mathrm{n} / \mathrm{a}$ \\
\hline 15 & $64 / \mathrm{M}$ & pos & pos & und & $\mathrm{n} / \mathrm{a}$ & $\mathrm{n} / \mathrm{a}$ & $\mathrm{n} / \mathrm{a}$ \\
\hline 16 & $52 / \mathrm{M}$ & pos & pos & und & $\mathrm{n} / \mathrm{a}$ & $\mathrm{n} / \mathrm{a}$ & $\mathrm{n} / \mathrm{a}$ \\
\hline 17 & $45 / \mathrm{M}$ & pos & pos & und & $\mathrm{n} / \mathrm{a}$ & $\mathrm{n} / \mathrm{a}$ & $\mathrm{n} / \mathrm{a}$ \\
\hline 18 & $63 / \mathrm{M}$ & pos & pos & und & $\mathrm{n} / \mathrm{a}$ & $\mathrm{n} / \mathrm{a}$ & $\mathrm{n} / \mathrm{a}$ \\
\hline \multicolumn{8}{|l|}{ Group C } \\
\hline 19 & $54 / \mathrm{M}$ & $\mathrm{n} / \mathrm{a}$ & $\mathrm{n} / \mathrm{a}$ & und & neg & neg & remission \\
\hline 20 & $45 / \mathrm{M}$ & $\mathrm{n} / \mathrm{a}$ & $\mathrm{n} / \mathrm{a}$ & und & pos & pos & persistent \\
\hline 21 & $46 / \mathrm{M}$ & $\mathrm{n} / \mathrm{a}$ & $\mathrm{n} / \mathrm{a}$ & und & neg & neg & remission \\
\hline 22 & $44 / \mathrm{F}$ & $\mathrm{n} / \mathrm{a}$ & $\mathrm{n} / \mathrm{a}$ & und & pos & pos & persistent \\
\hline 23 & $60 / \mathrm{M}$ & $\mathrm{n} / \mathrm{a}$ & $\mathrm{n} / \mathrm{a}$ & und & pos & neg & persistent \\
\hline 24 & $60 / \mathrm{M}$ & $\mathrm{n} / \mathrm{a}$ & $\mathrm{n} / \mathrm{a}$ & und & neg & neg & remission \\
\hline
\end{tabular}

$\mathrm{F}=$ female, $\mathrm{M}=$ male, pos=positive, neg=negative, und=undifferentiated, diff=differentiated, $\mathrm{n} / \mathrm{a}=$ not available

Group C patients had their combined examinations done during the post therapy. PET/CT was not performed at the earlier stage before the treatment as the facility was not accessible.

At presentation, the diagnosis of each patient was confirmed through the histopathological examination of tissue biopsy at Ospedale Niguarda in Milan or elsewhere and referred to the centre for the further evaluation and follow up.
Upon completion of the full course of radiotherapy or combined chemotherapy, group A and Group C patients were reassessed by the clinicians during the follow up visit at the clinic when they returned for the clinical assessment. Clinical signs and symptoms of recurrence like pain, epistaxis, neurological deficit or evidence of hearing impairment were sought for. The endoscopic examination looking for a direct evidence of the recurrent disease performed prior to 
imaging studies. In the routine practice, during the follow up, close monitoring for tumour recurrence or progression were accomplished using CT or MRI. In doubtful imaging findings, other than undergoing PET/CT examination, patients underwent biopsy. Eventually, the final diagnosis of the patient was made based upon the clinical evaluation as stated in the 'Disease status' column in Table 1.

\section{F-FDG PET/CT imaging}

Whole body FDG PET/CT scan was done at The Department of Nuclear Medicine, Ospedale Niguarda, Milan, Italy using integrated PET/CT system (Biograph, Siemens) combine dual slice spiral CT with a dedicated full-ring Bismuth Germanate (BGO) crystal for the PET scanner.

Following overnight fasting, PET/CT image acquisition was accomplished after 60 minutes waiting time following intravenous FDG injection. All examinations performed without intravenous contrast administration using the following protocol:

- CT Scanogram performed for planning the CT and PET study.

- A low dose CT acquisition was done first with parameters of $2.5 \mathrm{~mm}$ slices, spiral mode at $50 \mathrm{mAs}$ and $130 \mathrm{kV}$ for the anatomical correlation and attenuation correction of PET images. Immediately after CT acquisition, the table was positioned for PET acquisition. PET image acquisition was done at 5 min per bed position.

- A first acquisition was performed from the lung to the thighs in 3-dimensional mode. The second acquisition was performed from the vertex of the skull to the thoracic inlet.

- The reconstruction of the emission data was performed by using an iterative algorithm with software Somaris/5 VA40C and stored in a 128 matrix. CT-data were used for the attenuation correction. Volume projected images (transaxial, coronal and sagittal slices) and fusion images were generated for the interpretation.

- In post therapy patients, PET/CT imaging was done 20-24weeks post treatment, to avoid false positive results.

\section{Image interpretation and data analysis}

In our study, we include 37 paired imaging examinations. These consist of PET/ CT with CT or with MRI. Each method was interpreted separately and independently to assess primary tumour and cervical node status at two different stages, at the initial diagnosis and the following therapy by three experienced PET/CT specialists. Observation also includes evidence for distant metastasis.

On PET/CT images, results were derived from the visual analysis. Areas of the increased uptake, other than the normal physiological distribution, were considered as pathological. This was further confirmed through the semi quantitative analysis on the region of interest using Standardized Uptake Value (SUV). A value of more than 2.5 was pathological.

On CT or MR images, any pathological alterations to the normal anatomical boundaries as evident by distorted outline or presence of enhancing lesions in the studied areas are considered as pathological. Observations also include abnormal neck lymphadenopathies exceeding $10 \mathrm{~mm}$ in diameter. Lymph nodes of any size with central necrosis are also regarded as pathological.

\section{Statistical Analysis}

All the findings were tabulated to calculate the sensitivity, specificity and accuracy of the imaging modules. The negative and positive predictive values derived from these data. 


\section{Results}

\section{Patients}

From selected 24 patients in our study, we included 37 paired examinations of $\mathrm{PET} / \mathrm{CT}$ and CT or MRI. At diagnosis, the imaging results were compared with histopathological findings. At follow up, the standard was taken as the final clinical conclusion of disease status done by the clinicians following the clinical assessment. The summary of the findings of all enrolled patients are summarized in Table 1.

There were 17 (65\%) males and 7 (35\%) female patients. The age distribution was between 21 to 70 year-old with the highest frequency of patients aged at 61 years and above (Table 2).

\section{Comparing results between imaging modalities at diagnosis}

All 18 results at diagnosis were found to be concordant between PET/CT and CT or MRI. When these results were compared with standard (tissue biopsy), the calculated sensitivity and accuracy were found to be equally high (Table 4). Since there were no false negative or false positive results, the specificity is statistically void.

\section{Comparing results between imaging modalities for the assessment of the treatment response}

At imaging after the therapy, both methods are found to be equally accurate with high positive predictive values. The negative predictive value for PET/CT is found to be higher than the conventional imaging modalities $(100.0 \%$ for PET and $71.0 \%$ for conventional imaging) (Table 4). Overall, PET/CT provides a higher sensitivity in detecting the local recurrence disease as compared to the conventional imaging modality.
Table 2. Age distribution

\begin{tabular}{lll}
\hline Age (years) & Frequency & Percentage \\
\hline$<30$ & 1 & 4 \\
$31-40$ & 2 & 8.5 \\
$41-50$ & 6 & 25 \\
$51-60$ & 6 & 25 \\
61 and above & 9 & 37.5 \\
\hline Total & 24 & 100 \\
\hline
\end{tabular}

\section{Discussion}

Accuracy in staging NPC is most crucial during the post therapy evaluation at the follow up study. Centrally necrotic cervical nodes following the therapy may resemble the disease progression. The situation can be further complicated with the presence of reconstructive surgical procedures using graft and flap in this region.

While conducting this study, we found more significant variations in imaging results during the post treatment evaluation with a good statistical consensus at diagnosis.

There are no significant indifferences in the results at diagnosis since our study comprised of small number of patients. Furthermore, this retrospective selection of cases did not reflect the actual progress of clinical work flow for the patients investigated for suspicious NPC. This includes the identification of infected neck nodes or other nearby pathology at imaging which may resemble the clinical presentation of NPC. These are major contributions towards the variation in the statistic analysis.

In the post therapy evaluation of both imaging modalities at follow up, we found two false negative results on conventional imaging modalities (patient 12 and 23) and 1 false positive result on both imaging modalities including PET/CT (patient 6).

We re-evaluated the retrospective false negative results of the two patients on conventional imaging modalities and reach to 


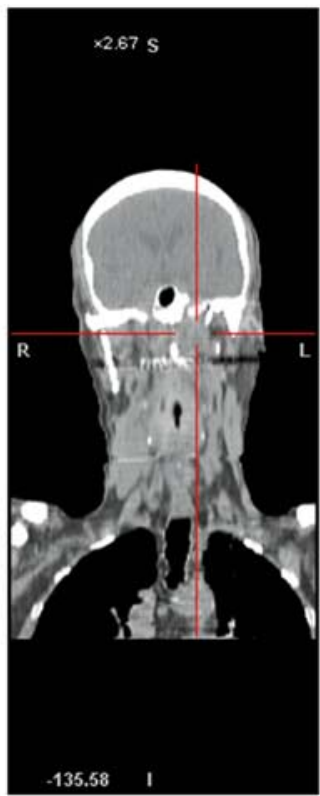

CT Coronals

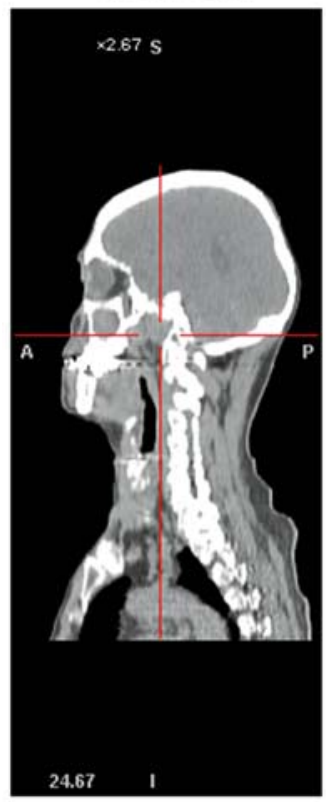

CT Sagittals

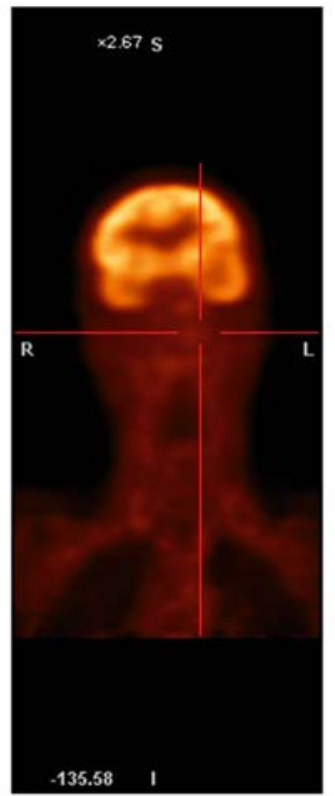

PET Coronals

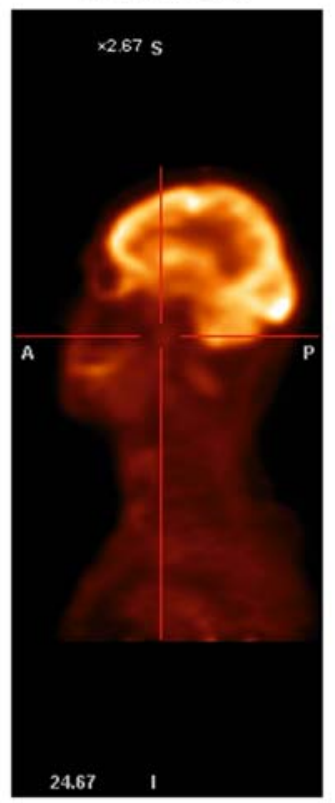

PET Sagittals

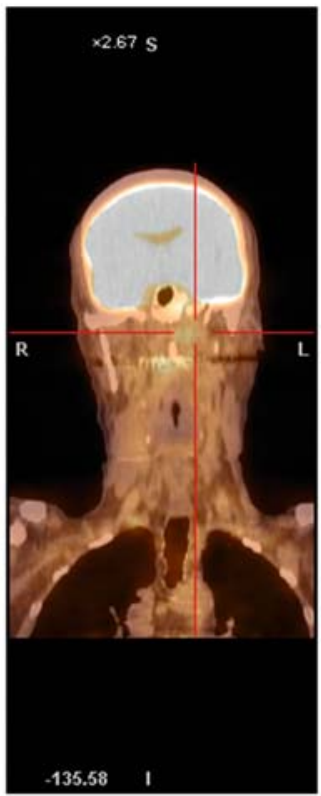

Fused Coronals

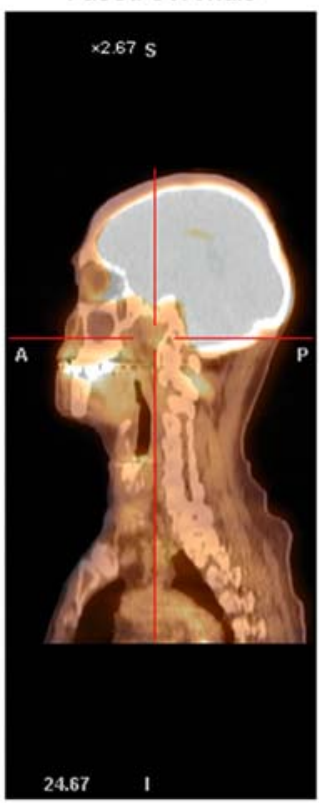

Fused Sagittals

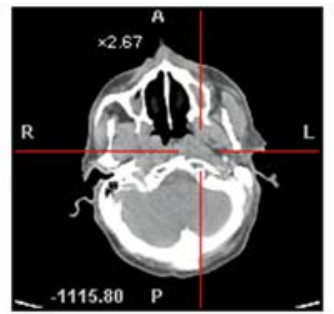

CT Transaxials

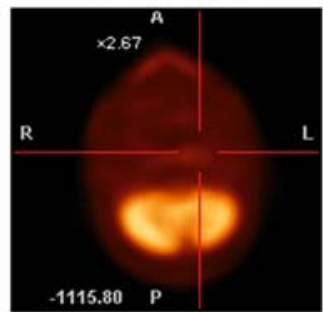

PET Transaxials

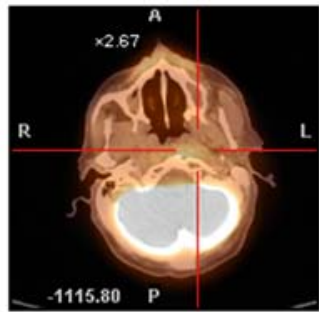

Fused Transaxials

Figure 2. Follow up ${ }^{18}$ F-FDG PET / CT imaging of the same patient 6 months upon completion of radiotherapy treatment demonstrating complete metabolic response in the left nasopharynx. Clinically the patient was found to be in complete remission.

an agreement that there were no significant anatomical disruption noted in the nasopharyngeal areas. Furthermore, no loco regional nodal involvement demonstrated in these patients. Thorough the search by the direct endoscopic visualization were the imaging findings confirmed. However, PET/CT evaluation demonstrated the lesion with a high metabolic activity indicating recurrent NPC. This particular clinical ex- 
Table 3. Comparative evaluation results between imaging modalities at diagnosis

\begin{tabular}{llllllll}
\hline Modality & TP & TN & FP & FN & $\begin{array}{l}\text { Sensitivity } \\
\%\end{array}$ & $\begin{array}{l}\text { Specificity } \\
\%\end{array}$ & $\begin{array}{l}\text { Accuracy } \\
\%\end{array}$ \\
\hline CT/MR & 18 & 0 & 0 & 0 & 100 & null & 100 \\
PET/CT & 18 & 0 & 0 & 0 & 100 & null & 100 \\
\hline
\end{tabular}

$\mathrm{TP}=$ true positive, $\mathrm{TN}=$ true negative, $\mathrm{FP}=$ false positive, $\mathrm{FN}=$ false negative

Table 4. Evaluation results for treatment response assessment between imaging modalities

\begin{tabular}{lllllllllll}
\hline Modality & TP & TN & FP & FN & $\begin{array}{l}\text { Total } \\
\text { exam }\end{array}$ & $\begin{array}{l}\text { Sensitivity } \\
\%\end{array}$ & $\begin{array}{l}\text { Specificity } \\
\%\end{array}$ & $\begin{array}{l}\text { Accuracy } \\
\%\end{array}$ & $\begin{array}{l}\text { PPV } \\
\%\end{array}$ & $\begin{array}{l}\text { NPV } \\
\%\end{array}$ \\
\hline CT/MR & 11 & 5 & 1 & 2 & 19 & 84 & 83 & 84 & 92 & 71 \\
PET/CT & 13 & 5 & 1 & 0 & 19 & 100 & 83 & 84 & 93 & 100 \\
\hline
\end{tabular}

$\mathrm{TP}=$ true positive, $\mathrm{TN}=$ true negative, $\mathrm{FP}=$ false positive, $\mathrm{FN}=$ false negative, $\mathrm{PPV}=$ positive predictive value, $\mathrm{NPV}=$ negative predictive value

ample has been described previously where $15.4 \%$ prevalence of residual or recurrent tumours are found to be beyond the reach of the routine nasopharyngeal biopsy. ${ }^{15}$ Therefore, the clinical assessment via endoscopic examination may missed deeply seated tumours whilst early tumour development may not manifest themselves clinically. Since conventional imaging modalities like CT or MRI are much dependent on anatomical alterations to be readily identified at imaging, this clinical example may have resulted in understaging or missed tumour lesions.

We also performed the re-evaluation study on the imaging results of the other patient. Because of doubtful positive imaging findings in the absence of signs and symptoms of the disease recurrence, the patient underwent biopsy of the nasopharynx which result was later found to be negative. The remission state was later confirmed at the subsequent follow-up. Thus, our reviewers came to an agreement that the altered anatomical landmark with reactivity following radio- and radio/chemotherapy may have been the cause for the false positive interpretation. Although we follow standard recommendations to perform imaging studies after 6 to 8 weeks post therapy period, variations in the rate of recovery and body response towards injury events caused by radiation or chemotherapy may differ from one patient to another. ${ }^{16,17}$ In addition, the possibility of a brief episode of the local inflammatory reaction at the time of imaging as a result of the infection cannot be totally segregated from the fact that there is a high metabolic activity in PET image acquisition.

The literature search suggested 18F-FDG PET was more specific than conventional imaging modalities in detecting residual or recurrent nodal metastasis in head and neck malignancies. The sensitivities in these articles cited ranging from $67 \%$ to $100 \%$ and specificities ranging from $77 \%$ to $100 \%{ }^{18-22}$ Our results are comparable with these findings (sensitivity $100 \%$ and specificity $83 \%$ ) supporting the assertion that 18F-FDG PET should be a sensitive tool in detecting residual or recurrent nodes in NPC. In fact, by incorporating CT into functional PET imaging, the percentage is expected to be higher as compared to PET imaging alone. The ability of PET in providing the functional metabolic activity of tumour infiltrated structures including small nodes is being utilized to enhance the superior capability of CT in demonstrating the precise anatomical location of these lesions. Thus, they 
are readily detectable on PET imaging and independent on the morphological changes in CT or MR images. The fusion of both imaging modalities in an integrated PET/CT machine should give better results. ${ }^{14,23-25}$ Furthermore, useful information can be obtained during a single seating and also time saving for the patient's convenience.

Within our small study population, we also demonstrated a higher negative predictive value of PET/CT in comparison to conventional imaging methods (Table 4). This finding signifies a more reliable negative PET/CT imaging result in circumstances when the actual disease is absent where the conventional imaging modality may have $29 \%$ chances of the false negative interpretation.

Our study encourages the use of PET/ CT in the post therapy management of NPC patients. We demonstrated the ability of PET/CT in correcting tumour under staging in two of our patients whose results were found to be falsely negative using the conventional imaging modality (patient 12 and 23). Aside from the treatment response assessment, PET/CT findings can also lead the clinicians in decision making on the choices of the clinical approach to be adopted. In the absence of clinical findings, a positive PET/CT result can be used as a general indicator for a more aggressive approach like biopsy in order to confirm the final diagnosis (patient number 6). This modality should be recommended as a preferable tool at follow up. ${ }^{26,27}$

Even though our findings at the post therapy assessment are relatively relevant, we suggest more research being granted for the assessment of actual value of PET/CT in therapy response within a larger cohort group of NPC patients.

\section{Conclusions}

The study found 18F-FDG PET/CT a suitable imaging modality to be utilized in managing patients with NPC especially at the post therapy follow-up. Further evidence is required to seek the actual value of this imaging modality at the initial stage of diagnosis and follow up within a larger cohort group.

\section{Acknowledgement}

Author wishes to express appreciation to The Department of Nuclear Medicine, Radiology Head and Neck Surgery, Ospedale Niguarda, Milan, Italy for kind hospitality and participation in this collaboration activity. This study was supported by unrestricted grants from Associazione Italiana per la Ricerca sul Cancro (AIRC) and Oncologia Ca' Granda Onlus (OCGO) Fondazione.

\section{References}

1. Chien YC, Chen JY, Liu MY, Yang HI, Hsu MM, Chen CJ, et al. Serologic markers of Epstein-Barr virus infection and nasopharyngeal carcinoma in Taiwanese men. N Engl J Med 2001; 345: 1877-82.

2. Mutirangura A, Tanunyutthawongese C, Pornthanakarem W, Kerekhanjanarong V, Sriuranpong V, Yenrundi S, et al. Genomic alterations in nasopharyngeal carcinoma: loss of heterozygosity and Epstein-Barr virus infection. Brit $J$ Cancer 1997: 76: 770-6.

3. Krishna SM, James S, Kattoor J, Balaram P. Serum EBV DNA as a biomarker in primary nasopharyngeal carcinoma of Indian origin. Jpn J Clin Oncol 2004; 34: 307-11.

4. Mutirangura A, Pornthanakanem $\mathrm{W}$, Theamboonlers A, Sriuranpong V, Lertsanguansinchi P, Yenrudi S, et al. Epstein-Barr viral DNA in serum of patients with nasopharyngeal carcinoma. Clin Cancer Res 1998; 4: 665-9. 
5. Tong JH, Tsang RK, Lo KW, Woo JK, Kwong J, Chan MW, et al. Quantitative Epstein-Barr virus DNA analysis and detection of gene promoter hypermethylation in nasopharyngeal (NP) brushing samples from patients with NP carcinoma. Clin Cancer Res 2002; 8: 2612-9.

6. Chang YS, Tyan YS, Liu ST, Tsai MS, Pao CC. Detection of Epstein-Barr virus DNA sequences in nasopharyngeal carcinoma cells by enzymatic DNA amplification. J Clin Microbiol 1990; 28: 2398402.

7. Macdonald MR, Le KT, Freeman J, Hui MF, Cheung RK, Dosch HM. A majority of inverted sinonasal papillomas carries Epstein-Barr virus genomes. Cancer 1995; 75: 2307-12.

8. Liavaag PG, Cheung RK, Kerrebijn JD, Freeman JL, Irish JC, Dosch HM. The physiologic reservoir of Epstein-Barr virus does not map to upper aerodigestive tissues. Laryngoscope 1998; 108: 42-6.

9. World Health Organisation International Agency for Research on Cancer (IARC) monographs on the evaluation of carcinogenic risks to humans Epstein-Barr virus and Kaposi's sarcoma herpesvirus/human herpesvirus 8. Summary of data reported and evaluation Epstein-Barr virus Kaposi's sarcoma 1997; 70: 47.

10. Twu CW, Wang WY, Liang WM, Jan JS, Jiang RS, Chao J, et al. Comparison of the prognostic impact of serum anti-EBV antibody and plasma EBV DNA assays in nasopharyngeal carcinoma. Int $\mathrm{J}$ Radiat Oncol Biol Phys 2007; 67: 130-7.

11. Strojan P. Cysteine cathepsins and stefins in head and neck cancer: an update of clinical studies. Radiol Oncol 2008; 42: 69-81.

12. Yip KW, Shi W, Pintilie M, Martin JD, Mocanu JD, Wong D, et al . Prognostic significance of the Epstein-Barrvirus, p53, Bcl-2, and surviving in nasopharyngeal cancer. Clin Cancer Res 2006; 12: 5726-32.

13. Avazpour I, Roslan RE, Bayat P, Saripan MI, Nordin AJ, Raja Abdullah RSA. Segmenting CT images of bronchogenic carcinoma with bone metastases using PET intensity markers approach. Radiol Oncol 2009; 43: 180-86.

14. Feinmesser R, Miyazaki I, Cheung R, Freeman JL, Noyek AM, Dosch HM. Diagnosis of nasopharyngeal carcinoma by DNA amplification of tissue obtained by fine-needle aspiration. $N$ Engl J Med 1992; 326: 17-21.
15. Chan SC, Ng SH, Chang JT, Lin CY, Chen YC, Chang $Y C$, et al. Advantages and pitfalls of 18F-fluoro-2-deoxy-D-glucose positron emission tomography in detecting locally residual or recurrent nasopharyngeal carcinoma: comparison with magnetic resonance imaging. Eur J Nucl Med Mol Imaging 2006; 33: 1032-40.

16. Ng SH, Joseph CT, Chan SC, Ko SF, Wang HM, Liao CT, et al. Clinical usefulness of 18F-FDG PET in nasopharyngeal carcinoma patients with questionable MRI findings for recurrence. J Nucl Med 2004; 45: 1669-76.

17. Tsai MH, Shiau YC, Kao CH, Shen YY, Lin CC, Lee CC. Detection of recurrent nasopharyngeal carcinomas with positron emission tomography using 18-fluoro-2-deoxyglucose in patients with indeterminate magnetic resonance imaging findings after radiotherapy. J Cancer Res Clin Oncol 2002; 128: $279-82$.

18. Kao CH, Shiau YC, Shen YY, Yen RF. Detection of recurrent or persistent nasopharyngeal carcinomas after radiotherapy with technetium- $99 \mathrm{~m}$ methoxyisobutylisonitrile single photon emission computed tomography and computed tomography: comparison with 18-fluoro-2-deoxyglucose positron emission tomography. Cancer 2002; 94: 1981-6.

19. Wong WL, Chevretton EB, McGurk M, Hussain K, Davis J, Beaney R, et al. A prospective study of PET-FDG imaging for the assessment of head and neck squamous cell carcinoma. Clin Otolaryngol 1997; 22: 209-14.

20. Kao CH, Chang Lai SP, Chieng PU, Yen RF, Yen TC. Detection of recurrent or persistent nasopharyngeal carcinomas after radiotherapy with 18-fluoro-2-deoxyglucose positron emission tomography and comparison with computed tomography. J Clin Oncol 1998; 16: 3550-5.

21. Kao CH, Tsai SC, Wang JJ, Ho YJ, Yen RF, Ho ST. Comparing 18-fluoro-2-deoxyglucose positron emission tomography with a combination of technetium $99 \mathrm{~m}$ tetrofosmin single photon emission computed tomography and computed tomography to detect recurrent or persistent nasopharyngeal carcinomas after radiotherapy. Cancer 2001; 92: 434-9.

22. Tsai MH, Shiau YC, Kao CH, Shen YY, Lin CC, Lee CC. Detection of recurrent nasopharyngeal carcinomas with positron emission tomography using 18-fluoro-2-deoxyglucose in patients with indeterminate magnetic resonance imaging findings after radiotherapy. J Cancer Res Clin Oncol 2002; 128: $279-82$. 
23. Krause BJ, Beyer T, Bockisch A, Delbeke D, Kotzerke J, Minkov V, et al. FDG-PET/CT in oncology. German guideline. Nuklearmedizin 2007; 46: 291-301.

24. Chua DT, Sham JS, Kwong DL, Au GK, Choy DT. Retropharyngeal lymphadenopathy in patients with nasopharyngeal carcinoma: a computed tomography-based study. Cancer 1997; 9: 869-77.

25. Gutzeit A, Antoch G, Kühl H, Egelhof T, Fischer M, Hauth E, et al. Unknown primary tumors: detection with dual-modality PET/CT-initial experience. Radiology 2005; 234: 227-34.

26. Paulus P, Sambon A, Vivegnis D, Hustinx R, Moreau P, Collignon J, et al. ${ }^{18}$ FDG-PET for the assessment of primary head and neck tumors: clinical, computed tomography, and histopathological correlation in 38 patients. Laryngoscope 1998; 108: 1578-83.

27. Ewald K, Mikosch P, Gallowitsch HJ, Kohlfurst $\mathrm{S}$, Lind $\mathrm{P}$. The value of imaging methods with emphasis on PET/CT in head and neck tumours: a comparison between a novel diagnostic regime using 18F-FDG PET and conventional techniques own results and literature review. Imaging Decisions 2007; 2: 24-32. 